\title{
Universiteit
}

Leiden

The Netherlands

\section{Pathways to psychosis: Help-seeking behavior in the prodromal phase} Rietdijk, J.; Hogerzeil, S.J.; Hemert, A.M. van; Cuijpers, P.; Linszen, D.H.; Gaag, M. van der

\section{Citation}

Rietdijk, J., Hogerzeil, S. J., Hemert, A. M. van, Cuijpers, P., Linszen, D. H., \& Gaag, M. van der. (2011). Pathways to psychosis: Help-seeking behavior in the prodromal phase.

Schizophrenia Research, 132(2-3), 213-219. doi:10.1016/j.schres.2011.08.009

Version: $\quad$ Not Applicable (or Unknown)

License: $\quad$ Leiden University Non-exclusive license

Downloaded from: https://hdl.handle.net/1887/117605

Note: To cite this publication please use the final published version (if applicable). 


\title{
Pathways to psychosis: Help-seeking behavior in the prodromal phase
}

\author{
Judith Rietdijk $^{\mathrm{a}, \mathrm{b}, *}$, Simon J. Hogerzeil ${ }^{\mathrm{a}}$, Albert M. van Hemert ${ }^{\mathrm{a}, \mathrm{c}}$, Pim Cuijpers ${ }^{\mathrm{b}}$, \\ Don H. Linszen ${ }^{\mathrm{d}}$, Mark van der Gaag a,b \\ a Parnassia Psychiatric Institute, Prinsegracht 63, 2512EX, The Hague, The Netherlands \\ ${ }^{\mathrm{b}}$ VU University Amsterdam and EMGO+ Institute of Health and Care Research Amsterdam, Department of Clinical Psychology, Van der Boechorststraat 1, 1081 BT, Amsterdam, \\ The Netherlands \\ ' Leiden University Medical Centre, Albinusdreef 2, 2333 ZA, Leiden, The Netherlands \\ ' Academic Medical Center, University of Amsterdam, Meibergdreef 5, 1105 AZ, Amsterdam, The Netherlands
}

\section{A R T I C L E I N F O}

\section{Article history:}

Received 13 May 2011

Received in revised form 28 July 2011

Accepted 14 August 2011

Available online 9 September 2011

\section{Keywords:}

Help-seeking

Prodromal

Psychosis

Pathways

\begin{abstract}
A B S T R A C T
Background: Knowledge of pathways to care by help-seeking patients prior to the onset of psychosis may help to improve the identification of at-risk patients. This study explored the history of help-seeking behavior in secondary mental health care services prior to the onset of the first episode of psychosis.

Method: The psychiatric case register in The Hague was used to identify a cohort of 1753 people in the age range of 18-35 at first contact who developed a psychotic disorder in the period from 1 January 2005 to 31 December 2009. We retrospectively examined the diagnoses made at first contact with psychiatric services. Results: 985 patients (56.2\%) had been treated in secondary mental health services prior to the onset of psychosis. The most common disorders were mood and anxiety disorders $(\mathrm{N}=385(39.1 \%))$ and substance use disorders $(\mathrm{N}=211(21.4 \%))$. Affective psychoses were more often preceded by mood/anxiety disorders, while psychotic disorder NOS was more often preceded by personality disorder or substance abuse. The interval between first contact and first diagnosis of psychosis was approximately 69 months in cases presenting with mood and anxiety disorders and 127 months in cases presenting with personality disorders. Discussion: This study confirms the hypothesis that the majority of patients with psychotic disorders had been help-seeking for other mental disorders in the secondary mental health care prior to the onset of psychosis. (c) 2011 Elsevier B.V. All rights reserved.
\end{abstract}

\section{Introduction}

Many risk factors contribute to the development of psychotic disorders. Some are distant, such as genetic and other pre- and perinatal risk factors (Harrison and Weinberger, 2005; Keshavan et al., 2005). Others are more proximal, such as cannabis abuse in adolescence (Moore et al., 2007). The development of psychopathology has in many cases been found to be a prodromal sign for the development of psychotic disorders. Social decline, depression and anxiety problems, sleeping problems, cognitive disturbances and psychotic-like experiences (PLEs) often precede the onset of psychosis (Häfner, 2000; Klosterkötter et al., 2001; Häfner et al., 2005b; Krabbendam and Van Os, 2005; Yung et al., 2005; Velthorst et al., 2010).

Retrospectively, PLEs almost always precede frank psychosis, but prospectively only $8 \%$ of new cases with PLEs in the general population develop a psychosis within 24 months (Hanssen et al., 2005).

PLEs do not differ in intensity in patients compared with nonpatients, but both groups do differ in their need for care (Stip and

\footnotetext{
* Corresponding author at: VU University Amsterdam and EMGO+ Institute of Health and Care Research Amsterdam, Van der Boechorststraat 1, 1081 BT, Amsterdam, The Netherlands. Tel.: + 31616514707.

E-mail address: j.rietdijk@parnassia.nl (J. Rietdijk).
}

Letourneau, 2009) and in the distress associated with the symptoms (Yung et al., 2006). Need for care and distress are important determinants of help-seeking behavior, and seeking help for disorders other than psychosis might be an important pathway to psychosis. It is also shown that people who report sub-clinical psychosis are more help-seeking than those subjects who do not report sub-clinical symptoms (Murphy et al., 2010). The combination of risk factors does raise the odds of developing a psychotic disorder. For instance, in a population-based study (NEMESIS) two or more sub-clinical psychotic symptoms with depressed mood result in a forty percent chance of developing a psychosis within 24 months (Hanssen et al., 2005).

A review by Anderson et al. (2010) found help-seeking behavior in $33-98 \%$ of patients who experienced a first psychotic episode. Some of the studies included in the review found that patients contacted their GPs before the onset of schizophrenia psychosis (Norman et al., 2004). Only two studies have explored help-seeking behavior during the prodromal stage in more detail. In a retrospective study in a cohort of 24 schizophrenia patients, 19 patients (75\%) sought help prior to the onset of psychosis (Bota et al., 2005). Of these patients, 14 were diagnosed with an Axis I diagnosis and 15 were prescribed medication or had a psychological intervention. Another retrospective study found evidence for prodromal disorders in $80 \%$ of 86 first-episode (schizophrenia) patients of whom $40 \%$ showed prodromal help- 
seeking behavior for these disorders (Addington et al., 2002). These proportions of help-seeking behavior ( 40 and $75 \%$ ) are based on small sample sizes, and a more accurate estimate of the prevalence of helpseeking behavior in larger populations entering the secondary mental health services before the onset of the disorder would be helpful.

Does help-seeking in secondary mental health services result in the detection of frank psychosis at a much earlier stage? Apparently it does not. Researchers found that the delay in secondary mental health care services was associated with a duration of untreated psychosis that was seven times longer than a direct referral to a first-episode psychosis department. They concluded that intervention is required in secondary as well as primary care services to reduce the duration of untreated psychosis (Brunet et al., 2007; Boonstra et al., 2008). Health care professionals do not seem to detect the development of psychosis when treating other disorders, or perhaps they are convinced that the psychotic symptoms are secondary to other problems. If a substantial proportion of patients who are likely to develop psychosis in the future do seek help in secondary mental health services, then screening for sub-clinical psychotic symptoms might be a strategy to prevent a lengthy period of untreated psychosis. Targeted intervention might even postpone or prevent a first psychotic episode. An important question remains: what proportion of people with a first psychotic episode has been help-seeking in health services at the prodromal stage?

In this study prodromal help-seeking behavior and diagnoses over time were retrospectively explored in all consecutive cases with a psychotic disorder recorded in a psychiatric case register during five years in a well-defined urban catchment area. Additionally, we examined the time between first contact and first diagnosis of psychotic disorder.

\section{Methods}

\subsection{Subjects}

The cohort of subjects was identified in the psychiatric case register of the Parnassia Psychiatric Institute $(N=1753)$. This institute has been the single provider of adult mental health care (18 years and over) in The Hague for over four decades. The Hague is one of the five largest cities of the Netherlands and the catchment area covers approximately 450,000 inhabitants. The psychiatric case register contains data about inpatient and outpatient service utilization as well as patient characteristics such as all the diagnosis and demographic information from the earliest contact on. This afforded the opportunity to examine the clinical history of patients who experienced a first episode of any psychotic disorder between 2005 and 2009. The current study explored the clinical help-seeking pathways of patients aged between 18 and 35. The 14-35 year age group is considered to have the highest risk of developing psychosis (DeLisi, 1992). However, Parnassia only provides adult care (18 years and over) and therefore we had to use the age criterion of 18-35 years.

The inclusion criteria for this study were:

1) The development of a first registered DSM IV-diagnosis of affective (schizoaffective disorder, bipolar disorder or mood disorder with psychotic features) or non-affective psychosis (schizophrenia and other psychotic disorders) between January 2005 and December 2009;

2) Age between 18 and 35 years at first contact with Parnassia;

3) Residence in The Hague.

Excluded were patients with substance-induced psychotic disorders.

\subsection{Statistical analyses}

The distribution assumptions of the data were tested and did not meet the criteria for parametric tests. Non-parametric Mann-
Whitney-tests, Kruskal-Wallis tests and two-tailed multinomial logistic regression were applied for differences in time between first contact and transition into psychosis for the different psychotic diagnoses and the different first-contact diagnoses. Mann-Whitney-U tests were used to follow up significant findings of the Kruskal-Wallis tests. We used Bonferroni correction to ensure the Type I errors did not build up to more than a .05 level of significance (critical value of .05 divided by the number of Mann-Whitney-U tests we have conducted). Kaplan-Meier analysis was performed for survival analyses: this study uses backward recurrence times. The KaplanMeier analysis is therefore only used to explore the time from first contact until diagnosis in the psychosis spectrum (Allison, 1985). Chisquare analyses were used to test the association between type of psychotic onset and clinical history. Adjusted standardized residuals of chi-square cross-tabulation analyses were conducted between first contact diagnosis and psychotic disorders in which negative adjusted residuals in a cell correspond to a smaller number of cases than expected by chance and positive residuals correspond to more cases (corrected for small $\mathrm{N}$ in the groups).

\section{Results}

\subsection{Subjects}

In the years 2005 to 2009, 1753 people aged between 18 and 35 years at first contact with Parnassia were diagnosed with a psychotic disorder: 1015 men and 738 women. The mean age of first contact with services was $26.0(\mathrm{SD}=5.1$, median $=26.0)$ and the mean age when diagnosed with psychosis was $32.1(\mathrm{SD}=7.9$, median $=32.0)$ years.

\subsection{First contact diagnoses}

Fig. 1 displays the help-seeking pathways to psychosis: 768 (43.8\%) patients were diagnosed with schizophrenia spectrum (schizophrenia, schizophreniform disorder, schizoaffective disorder and delusional disorder) (DSM 295.xx and 297.1), psychotic disorder NOS including brief psychotic disorder (DSM 298.xx) or affective psychotic disorder (bipolar disorder and depression with psychotic features, DSM 296.xx) at first contact. Women were overrepresented in the group with affective psychosis $(\mathrm{N}=137 ; 62.8 \%)$, and men were more often diagnosed in the schizophrenia spectrum $(\mathrm{N}=222 ; 72.1 \%)$ and with psychotic disorder NOS $(\mathrm{N}=409 ; 67.7 \%)$ at first contact.

Of those patients who were diagnosed with affective psychotic disorders, fewer than expected were psychotic at first contact (see Table 1). Conversely, patients diagnosed with non-affective psychosis were more often psychotic at first contact. Men were more often diagnosed with a psychotic disorder at first contact.

A total of 985 patients (56.2\%) had a history of treatment for nonpsychotic Axis I or II disorders before the onset of the first psychotic episode (see Fig. 1). The largest groups of these patients had been referred for treatment for anxiety and mood disorders, substance use disorders and adjustment disorders. Whereas women had more anxiety, mood and adjustment disorders in the help-seeking history, men had been treated more often for substance use and personality disorders.

The diagnoses at first contact and estimated time to diagnosis of psychotic disorder are presented in Table 2.

\subsection{Time between first contact and psychosis}

To measure the mean time from first contact to first diagnosis of psychosis among patients who entered the secondary mental health care services for other mental problems, we excluded those patients who were diagnosed with psychosis at first contact from the analysis. It took 86.6 months ( $\mathrm{se}=2.04$ ) to be diagnosed in the psychosis spectrum from first contact for non-psychotic disorders; the median 


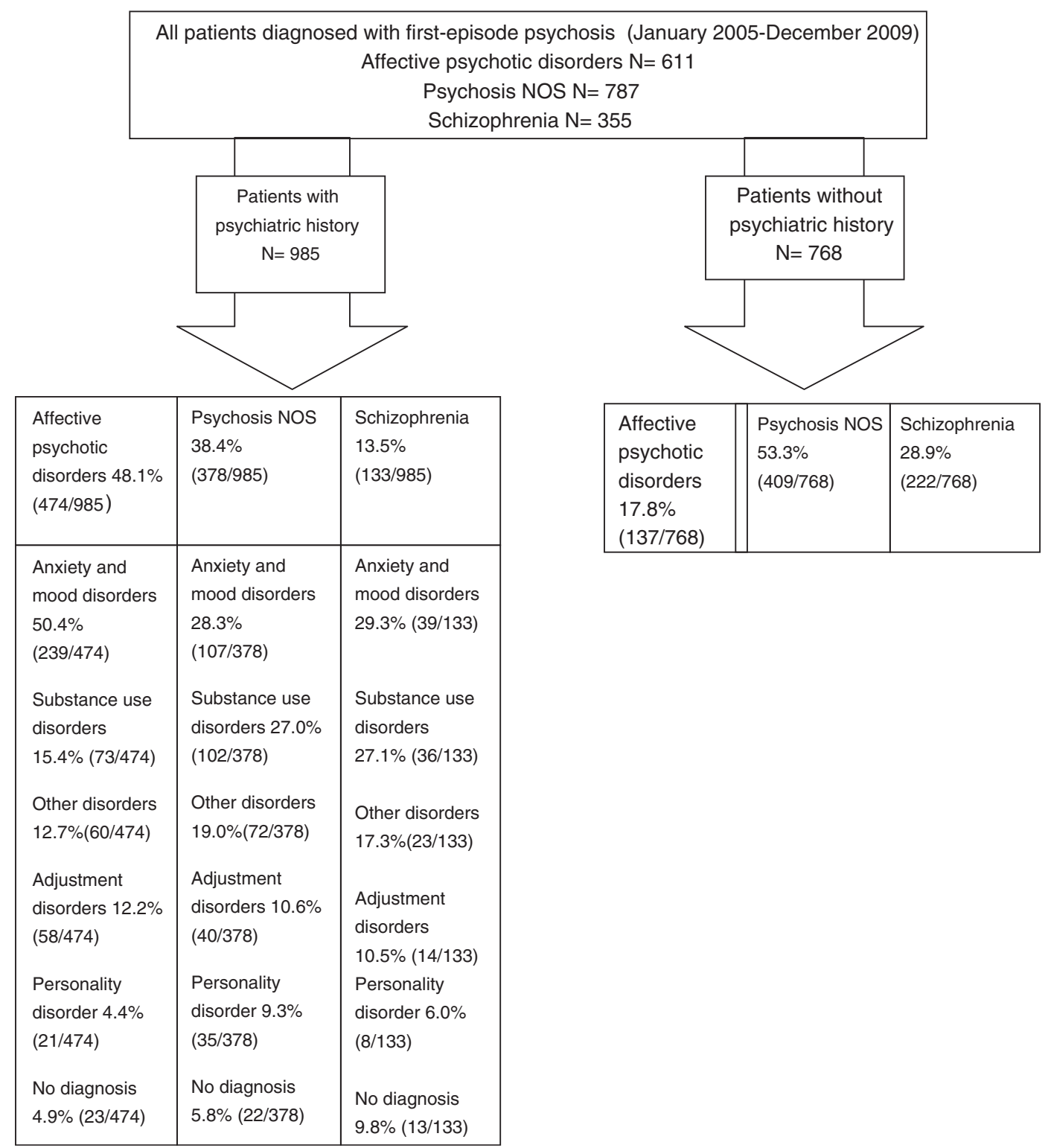

Fig. 1. Patients with and without a psychiatric history and their initial diagnoses.

Table 1

The likelihood of psychiatric treatment in the prodromal stage of a psychotic disorder.

\begin{tabular}{|c|c|c|c|}
\hline & $\begin{array}{l}\text { Psychotic disorder } \\
\text { at first contact } \\
(\mathrm{N}=768)\end{array}$ & $\begin{array}{l}\text { No psychotic disorder } \\
\text { at first contact } \\
(\mathrm{N}=985)\end{array}$ & $\chi^{2}$ \\
\hline $\begin{array}{l}\text { Affective psychotic } \\
\text { disorder }^{\mathrm{a}} \\
(\mathrm{N}=611)\end{array}$ & $\boldsymbol{\nabla}(\mathrm{N}=137)$ & $\Delta \mathbf{\Delta}(\mathrm{N}=474)$ & $\begin{array}{l}\chi^{2}(2,1753)= \\
174.3, p<.001\end{array}$ \\
\hline $\begin{array}{l}\text { Psychotic disorder } \\
\text { NOS }(\mathrm{N}=787)\end{array}$ & $\boldsymbol{\Delta}(\mathrm{N}=409)$ & $\boldsymbol{\nabla}(\mathrm{N}=378)$ & $\begin{array}{l}\chi^{2}(2,1753)= \\
38.6, p<.001\end{array}$ \\
\hline $\begin{array}{l}\text { Schizophrenia } \\
\qquad(\mathrm{N}=355)\end{array}$ & $\boldsymbol{\Delta}(\mathrm{N}=222)$ & $\boldsymbol{\nabla}(\mathrm{N}=133)$ & $\begin{array}{l}\chi^{2}(2,1753)= \\
63.4, p<.001\end{array}$ \\
\hline Male $(\mathrm{N}=1015)$ & $\boldsymbol{\Delta}(\mathrm{N}=488)$ & $\boldsymbol{\nabla}(\mathrm{N}=527)$ & $\begin{array}{l}\chi^{2}(1,1753)= \\
25.1, p<.001\end{array}$ \\
\hline \multicolumn{4}{|c|}{$\begin{array}{l}\Delta \boldsymbol{\Delta} \text { or } \boldsymbol{\nabla \nabla} \text { : adjusted standardized residuals }>|10| \text { or }<|-10| \\
\Delta \text { or } \boldsymbol{\nabla} \text { : adjusted standardized residuals }>|5| \text { or }<|-5|\end{array}$} \\
\hline
\end{tabular}

Chi-square cross-tabulation analysis between the initial disorder and transition diagnosis in which adjusted standardized residuals reflect a higher or lower number of cases than expected, corrected for small $\mathrm{N}$. Negative adjusted residuals in a cell correspond to a smaller number of cases than expected by chance, positive residuals correspond to more cases. Adjusted standardized residuals outside the range -2.5 and +2.5 indicate significant differences between observed and expected numbers.

a Bipolar disorder and mood disorders with psychotic features. was 78.0 months (Table 2). About $23 \%$ made the transition to psychosis in the first two years.

No differences were found in mean time between first contact and first psychotic diagnosis for the various clusters of psychosis (Kruskal-Wallis: $\mathrm{H}(2)=3.03, p=.219$ ). The Mann-Whitney-U test was used to measure the effect of gender on mean time to transition. The difference between mean time from first contact to psychosis in men $($ mean $=94.8, \mathrm{SD}=67.8$, median $=99.0$ months) compared with women (mean $=78.5, \mathrm{SD}=71.2$, median $=66.0$ months) was statistically significant $(U=100,054, z=4.6, p<.001)$.

The mean time between first contact and first-episode psychosis differed for first contact diagnosis (Kruskal-Wallis: $\mathrm{H}(5)=82.6$, $p<.001)$. Mann-Whitney-U tests were used to follow-up this finding. A Bonferroni correction was applied. Al effects were reported at a .0016 level of significance $(.05 / 30)$. People first diagnosed with anxiety and mood disorders, adjustment disorders and other disorders developed psychosis sooner than people with no diagnosis, substance use problems or personality disorders at first contact. Regression analysis was used to correct for age at first contact, gender and type of psychotic onset, and the differences in mean time to psychosis diagnoses for the first contact diagnosis remained 
Table 2

The characteristics of people with a non-psychotic diagnosis preceding psychotic disorder.

\begin{tabular}{|c|c|c|c|c|c|c|}
\hline $\begin{array}{l}\text { Initial diagnosis } \\
\text { (clustered) }\end{array}$ & $\mathrm{N}$ & Female & $\begin{array}{l}\text { Mean age at first } \\
\text { contact in years (se) }\end{array}$ & $\begin{array}{l}\text { Mean age at first } \\
\text { psychosis in years (se) }\end{array}$ & $\begin{array}{l}\text { Mean time from first contact to diagnosis } \\
\text { of psychotic disorder in months (se) }\end{array}$ & $\begin{array}{l}\text { Median time in months to } \\
\text { diagnosis of psychotic disorder }\end{array}$ \\
\hline Anxiety and mood disorders & 385 & $215(55.8 \%)$ & $27.5(.23)$ & $33.4(.32)$ & $70.0(2.92)$ & 56 \\
\hline Substance use & 211 & $37(17.5 \%)$ & $26.2(.33)$ & $35.8(.50)$ & $115.1(3.98)$ & 127 \\
\hline Other disorders ${ }^{\mathrm{a}}$ & 155 & $88(56.8 \%)$ & $26.2(.40)$ & $32.7(.65)$ & $78.2(6.23)$ & 67 \\
\hline Adjustment disorders & 112 & $59(52.7 \%)$ & $27.8(.43)$ & $34.3(.65)$ & $77.5(5.71)$ & 62 \\
\hline Personality disorder & 64 & $26(40.6 \%)$ & $26.1(.60)$ & $36.6(.90)$ & $125.3(8.22)$ & 129 \\
\hline Not diagnosed & 58 & $33(56.9 \%)$ & $25.9(.64)$ & $33.5(.85)$ & $91.2(6.6)$ & 88 \\
\hline Total & 985 & $458(46.5 \%)$ & $26.9(.15)$ & $34.2(.22)$ & $86.6(2.04)$ & 78 \\
\hline
\end{tabular}

a Other disorders are disorders that are not very common in this dataset, e.g. sexual disturbances, relationship problems or eating disorders.

significant $(\mathrm{F}(4980)=21.8, p<.001)$. Fig. 2 shows the survival curves for the various first contact diagnoses and shows the same differences in time to transition for the various first contact disorders.

\subsection{Onset of psychosis}

The clinical history is shown in Table 3 and varied between the psychosis subtypes. Whereas patients diagnosed with bipolar disorders were more likely to have had anxiety and mood disorders in the prodromal phase, patients with psychosis NOS were more often diagnosed with premorbid substance use disorders, other disorders and personality disorders.

\section{Discussion}

\subsection{Pathways to psychosis}

This study explored the clinical help-seeking pathway to psychosis. Of the patients $(\mathrm{N}=985)$ who had been diagnosed within the

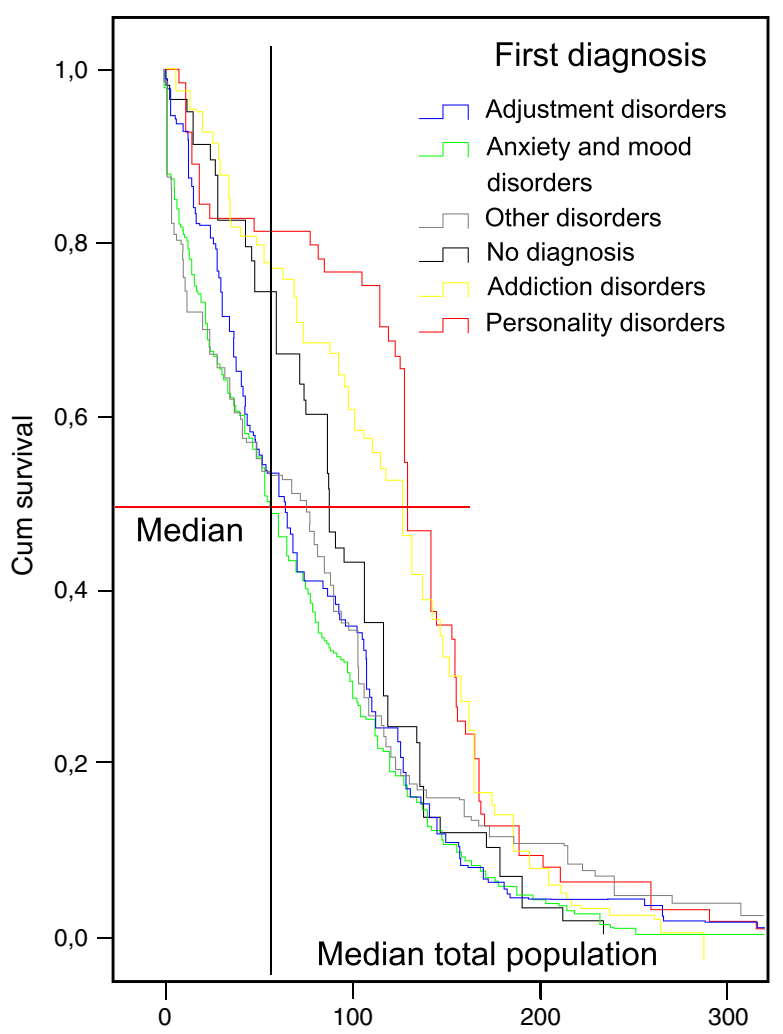

Fig. 2. Survival curve for transition to psychosis after accessing secondary mental health service for each initial diagnosis separately. Months between first contact and psychosis. psychosis spectrum, 56.2\% had received treatment in the secondary mental health services for various non-psychotic disorders prior to the onset of psychosis. The most common prodromal disorders were anxiety and mood disorders. High rates were also found for substance use disorders and adjustment disorders. The average time from first contact to transition into psychosis was 87 months. Patients with anxiety and mood disorders (69 months) developed a first-episode psychosis significantly sooner than those who sought help for personality disorders (127 months).

The various types of psychotic disorders were associated with different pathways to care. The patients who were psychotic at first contact were mostly diagnosed with schizophrenia and psychosis NOS, whereas the help-seeking group were dominated by affective psychosis. Several Axis I and II disorders precede the onset of

Table 3

The association between initial diagnosis and psychotic disorder subgroup.

\begin{tabular}{|c|c|c|c|}
\hline & $\begin{array}{l}\text { Affective psychotic } \\
\text { disorders }^{\mathrm{a}}\end{array}$ & $\begin{array}{l}\text { Psychotic } \\
\text { disorder NOS }\end{array}$ & Schizophrenia \\
\hline $\begin{array}{c}\text { Anxiety and mood } \\
\text { disorders count }\end{array}$ & $\mathrm{N}=277$ & $\mathrm{~N}=134$ & $\mathrm{~N}=46$ \\
\hline Expected count & $\mathrm{N}=220$ & $\mathrm{~N}=177$ & $\mathrm{~N}=61$ \\
\hline $\begin{array}{l}\text { Standardized adjusted } \\
\text { residuals }\end{array}$ & 6.9 & -5.3 & -2.6 \\
\hline Substance use count & $\mathrm{N}=93$ & $\mathrm{~N}=120$ & $\mathrm{~N}=41$ \\
\hline Expected count & $\mathrm{N}=122$ & $\mathrm{~N}=98$ & $\mathrm{~N}=34$ \\
\hline $\begin{array}{l}\text { Adjusted standardized } \\
\text { residuals }\end{array}$ & -4.1 & 3.2 & 1.5 \\
\hline $\begin{array}{l}\text { Other disorders }{ }^{\mathrm{b}} \\
\text { count }\end{array}$ & $\mathrm{N}=65$ & $\mathrm{~N}=87$ & $\mathrm{~N}=25$ \\
\hline Expected count & $\mathrm{N}=85$ & $\mathrm{~N}=68$ & $\mathrm{~N}=24$ \\
\hline $\begin{array}{l}\text { Adjusted standardized } \\
\text { residual }\end{array}$ & -3.3 & 3.1 & .4 \\
\hline $\begin{array}{l}\text { Adjustment disorders } \\
\text { count }\end{array}$ & $\mathrm{N}=74$ & $\mathrm{~N}=45$ & $\mathrm{~N}=17$ \\
\hline Expected count & $\mathrm{N}=65$ & $\mathrm{~N}=53$ & $\mathrm{~N}=18$ \\
\hline $\begin{array}{l}\text { Adjusted standardized } \\
\text { residuals }\end{array}$ & 1.6 & -1.4 & -.3 \\
\hline $\begin{array}{l}\text { Personality disorder } \\
\text { count }\end{array}$ & $\mathrm{N}=24$ & $\mathrm{~N}=39$ & $\mathrm{~N}=10$ \\
\hline Expected count & $\mathrm{N}=35$ & $\mathrm{~N}=28$ & $\mathrm{~N}=10$ \\
\hline $\begin{array}{l}\text { Standardized } \\
\text { residuals }\end{array}$ & -2.7 & 2.7 & 0 \\
\hline No diagnosis count & $\mathrm{N}=25$ & $\mathrm{~N}=24$ & $\mathrm{~N}=15$ \\
\hline Expected count & $\mathrm{N}=31$ & $\mathrm{~N}=25$ & $\mathrm{~N}=9$ \\
\hline $\begin{array}{l}\text { Adjusted standardized } \\
\text { residuals }\end{array}$ & -1.5 & -.2 & 2.5 \\
\hline$\chi^{2}$ & $\begin{array}{l}\chi^{2}(5,985)= \\
59.3, p<.001\end{array}$ & $\begin{array}{l}\chi^{2}(5,985)= \\
38.9, p<.001\end{array}$ & $\begin{array}{l}\chi^{2}(5,985)= \\
59.3, p<.001\end{array}$ \\
\hline
\end{tabular}

Chi-square cross-tabulation analysis between the initial disorder and psychotic disorder subgroup diagnosis in which adjusted standardized residuals reflect a higher or lower number of cases than expected, corrected for small N. Negative adjusted residuals in a cell correspond to a smaller number of cases than expected by chance, positive residuals correspond to more cases. Adjusted standardized residuals outside the range -2.5 and +2.5 indicate significant differences between observed and expected numbers.

a Bipolar disorder and mood disorders with psychotic features.

b Other disorders are disorders that are not very common in this dataset, e.g. sexual disturbances, relationship problems or eating disorders. 
psychosis, but patients who had been diagnosed with affective psychosis had been seeking help more often for mood and anxiety disorders, whereas patients with psychotic disorder NOS reported more premorbid substance use disorders and personality disorders. Furthermore, the analyses found gender differences. Women sought help in secondary mental health care services more often prior to the onset of psychosis than men and women were more likely to develop affective psychosis, whereas men were more often diagnosed with schizophrenia after onset of psychosis.

The results of the present study are in line with the reported findings in previous small studies of schizophrenia patients (Addington et al., 2002; Bota et al., 2005), which found a prodromal helpseeking pathway in $40-75 \%$ of the patients with schizophrenia. They reported mainly symptoms of depression. Häfner et al. showed that eight out of ten most frequent initial symptoms were shared by the group with severe depression and the group with prodromal symptoms of schizophrenia. In patients with schizophrenia, these symptoms precede and overlap with negative symptoms (Häfner et al., 2005a). Studies of high-risk patients also reported a help-seeking pathway in approximately 50\% of the patients (Preda et al., 2002; Platz et al., 2006).

Although we also found mood and anxiety disorders to be the most prevalent disorders in the help-seeking history (39\% of the population), the results show that patients who were diagnosed with psychotic syndromes were help-seeking in the prodromal phase for all kinds of Axis I and Axis II disorders. The high rate of anxiety and mood disorders in the prodromal stage is probably due to the fact that mood and anxiety disorders are quite common in the general population (Bijl et al., 1998). It might be that there are no distinct help-seeking pathways to psychosis; psychotic symptoms are prevalent in several Axis I and II disorders (Eaton et al., 2007) and interact with non-psychotic symptoms until they cross the threshold of frank psychosis. Schizophrenia in particular was not associated with specific prodromal disorders. So, not only mood and anxiety disorders are risk factors for developing psychosis, but psychopathology in general is a risk factor as well.

After the transition into psychosis, diagnoses fluctuate over time as well. In a sample of first-episode patients, only 30-40\% meet the criteria for a disorder in the schizophrenia spectrum (McGorry et al., 2008). The other patients are diagnosed with other psychotic disorders and can be seen as having a risk for developing schizophrenia in the future as the percentage that will progress to schizophrenia will increase over time. Furthermore, patients once diagnosed with schizophrenia could be diagnosed with affective psychosis later on. This might be the result of a lack of specificity of symptoms of schizophrenia and related psychotic disorders (Eaton et al., 2007); symptoms can be seen in patients suffering from other disorders (e.g. negative symptoms versus depressive symptoms) and even in the general population (Van Os et al., 2000). It makes sense to examine psychotic disorders from a dimensional perspective, i.e. with psychotic symptoms on a continuum of severity, in contrast to the previous categorical or dichotomous perspective (Van Os et al., 2000).

The results show that many psychotic people were treated for substance use problems prior to the onset of psychosis. This is in line with findings that substance use - cannabis use in particular - is a risk factor for developing psychotic symptoms (Moore et al., 2007; Murray et al., 2010). Cannabis use contributes to a complex set of risk factors and vulnerability (Arseneault et al., 2004).

The mean time from first contact to the diagnosis of psychotic disorder was 87 months and therefore much higher than the mean time of 32 months found in the study by Bota et al. (2005). This is perhaps due to the fact that we measured time to transition into psychosis plus time to diagnosis. As mentioned, patients who were in treatment with secondary services for non-psychotic disorders in the prodromal stage had seven times longer duration of untreated psychosis after onset of psychosis than patients who were psychotic at first contact (Norman et al., 2004; Brunet et al., 2007; Boonstra et al., 2008). In addition, psychological treatments targeting non-psychotic mental disorders, but also anti-psychotic and anti-depressive medications, may have decreased the distress with sub-clinical psychotic symptoms as well. The final common pathway from prodromal stage to psychosis is characterized by catastrophizing interpretations of psychoticlike symptoms and end in highly emotional secondary delusion on such things as the origin and purpose of voices. Cognitive behavior therapy, anti-psychotic medication or anti-depressive medication reduce emotional arousal (French et al., 2003; French and Morrison, 2004). As a result, treatment in secondary mental health care may have delayed the onset of psychosis.

\subsection{First-episode population}

We have found a different population than populations reported in other first-episode studies (Addington et al., 2002; Bota et al., 2005). The mean age of psychotic onset in studies is mainly the result of the selected age range of the recruitment population. Research populations are restricted by age criteria (e.g. inclusion till the age of 35), ignoring the fact that - although the risk of developing psychosis decreases with age - older people can suffer from a first episode of psychosis as well. For instance, recruitment in adolescent populations found a mean onset age of 19 or 20 (Morrison et al., 2011; Yung et al., 2011). Häfner et al. found a mean age at first admission in hospital of 29 years for psychosis and even of 31 for schizophrenia in an adult population (Häfner et al., 1993). As Parnassia only provides adult care (18 years and over), the mean age is higher than the mean age in adolescent populations, but comparable to the mean age found by Häfner et al. In addition, this study used an age range of 18-35 years at intake for non-psychotic disorders, but had no restricted age criteria for the onset of psychosis. This means that late onsets are also present in the current study. Women in particular are associated with late onset of psychosis. In contrast to other studies reporting on firstepisode cohorts, we included almost 50\% women. This suggests that these (older) women might be overlooked in studies of young firstepisode cohorts (DeLisi, 1992; Häfner et al., 1993).

We found that women were inclined to seek help prior to the onset of psychosis more often than men. This is in accordance with the findings that women tend to seek mental help more often and at an earlier stage of the illness than men (Lane and Addis, 2005). Women were more likely to be diagnosed with anxiety and mood disorders, and men with non-affective psychosis and substance use disorders at first contact. Affective symptoms, social conflict and help-seeking are more often associated with psychotic disorder in females, while negative symptoms and cognitive limitations characterize the developmental impairment in male psychotic disorder (Van Os et al., 2010).

\subsection{Clinical implications}

The results of this study could contribute to the improvement of early detection strategies. Both the low incidence of psychotic disorders and high prevalence of psychotic symptoms in the population create a compelling need to find samples with a heightened psychosis proneness in order to be able to identify people at risk for developing psychosis. Most early detection services use referral by primary caretakers as an enrichment strategy. However, recognizing those patients that go on to develop psychosis may be particularly challenging as the early symptoms resemble the early symptoms of depression or anxiety (Häfner et al., 2005b). The results of this study show that the majority of people who developed a psychotic disorder had been help-seeking in the prodromal stage. This opens the opportunity for the implementation of a closing-in strategy in secondary mental health care services that combines several risk factors; this is required in order to filter out a sample with a high base 
rate of at-risk people to reduce the number of false positives (McGorry et al., 2003; Van Os and Delespaul, 2005). Although the current results give no information about the prevalence of cases compared with non-cases and therefore no information about the psychosis proneness of the general help-seeking population, we can safely assume that the prevalence of psychosis proneness is higher in the helpseeking population than in the general population. The estimated lifetime prevalence of mental disorders is $25 \%$ in the population at large (Volleberg et al., 2010); 60\% of the psychotic people who seek help in the prodromal phase are part of this small group. This is in line with the expectation of Van Os and Delespaul (2005), who estimated the prevalence of schizophrenia in secondary mental health care services at $7 \%$, compared with a prevalence of $0.6 \%$ in the general population.

\subsection{Strengths and limitations}

The major strength of the current study is that the sample is based on data of all consecutive cases of psychotic disorder in the catchment area within a five-year time frame. The sample has no selection bias. It is an epidemiologically representative sample with strong external validity.

Another strength of this study is that in using the psychiatric case register it has access to all the diagnostic information about the patients from the first contact with the mental health provider to date, reducing the likelihood of recall bias when data are collected retrospectively by interviewing. The diagnoses were made in accordance with the guidelines of the DSM IV.

A limitation of our study is the fact that the duration of untreated psychosis is included in the time leading up to a diagnosis of psychotic disorder. The longer mean time before psychotic disorder diagnosis could be the result of a considerably longer delay in diagnosing psychotic disorder (Brunet et al., 2007; Boonstra et al., 2008).

A second limitation is that we have no knowledge about the treatment history of patients who previously had contact with child and adolescent psychiatric services. Parnassia only provides adult care ( 18 and over). The relatively high age of onset could be caused by failure to include some of the youngest first contacts with a psychotic disorder. In addition, it is unknown whether patients received treatment by primary services (e.g. GPs, psychiatric nurses or psychologists). In 2001 almost $5.5 \%$ of the Dutch population was prescribed anti-depressants - in $80 \%$ of cases by their GPs (Baan et al., 2003). Being unaware of treatment by GPs and primary care services, we have some false negatives in the sample. These patients were regarded as having no history of help-seeking behavior. The number of help-seeking patients in the prodromal stage has been slightly underestimated. On the other hand, we explored whether there is a possibility of detecting high-risk patients in secondary mental health care services and we were therefore looking for evidence that the majority of psychotic people had been using these services for other mental problems preceding the first episode of psychosis.

A third limitation is that our dataset did not include information on treatments. Non-psychotic patients were perhaps prescribed antipsychotic medication off-label. Although antipsychotic medication prescription to patients with sub-clinical psychotic symptoms is not recommended in clinical practice guidelines, research showed that $21 \%$ of high-risk patients used antipsychotic medication without being full-blown psychotic (Nieman et al., 2009).

\section{Conclusion}

The majority of people who have developed a psychotic disorder had been help-seeking for other mental disorders in the prodromal period. Not all those with mental problems will develop a psychosis, but a selection of people with, for example, depression and PLEs probably have an elevated risk of developing a psychosis in the near future. The findings of this study encourage the identification of patients at risk of developing a psychotic disorder in a help-seeking population in secondary mental health care.

\section{Role of funding source}

ZonMW had no further role in the study design; in the collection, analysis and interpretation of data; in the writing of the report; and in the decision to submit the paper for publication.

\section{Contributors}

All authors contributed to the study. J. Rietdijk and M. van der Gaag designed the study. J. Rietdijk managed the literature searches, statistical analyses and drafted the article. S. Hogerzeil and A. M. van Hemert prepared the database for analysis and helped to draft the article. M. van der Gaag, D. Linszen and P. Cuijpers helped to draft the article. All authors provided comments, and read and approved the final manuscript.

\section{Conflict of interest}

The authors declare that they have no competing interests.

\section{Acknowledgments}

This study was supported by The Netherlands Health Research Council, (ZonMW), The Hague 120510001; NTR1085 (Principal Investigator M. van der Gaag PhD).

\section{References}

Addington, J., Mastrigt, S.V., Hutchinson, J., Addington, D., 2002. Pathways to care: help seeking behaviour in first episode psychosis. Acta Psychiatr. Scand. 106, 358-364.

Allison, P.D., 1985. Survival analysis of backward recurrence times. J. Am. Stat. Assoc. 80, 315-322.

Anderson, K.K., Fuhrer, R., Malla, A.K., 2010. The pathways to mental health care of firstepisode psychosis patients: a systematic review. Psychol. Med. 40, 1585-1597.

Arseneault, L., Cannon, M., Witton, J., Murray, R.M., 2004. Causal association between cannabis use and psychosis: examination of the evidence. Br J Psychiatry 184 111-117.

Baan, C.A., Hutten, J.H., Rijken, P.M., 2003. [in Dutch] Afstemming in de zorg. Een achtergrondstudie naar de zorg voor mensen met een chronische aandoening. RIVM/NIVEL, Bilthoven.

Bijl, R.V., Zessen, G.V., Ravelli, A., Rijk, C.D., Langendoen, Y., 1998. The Netherlands Mental Health Survey and Incidence Study (NEMESIS): objectives and design. Soc. Psychiatry Psychiatr. Epidemiol. 33, 581-586.

Boonstra, N., Wunderink, L., Sytema, S., Wiersma, D., 2008. Detection of psychosis by mental health care services; a naturalistic cohort study. Clin. Pract. Epidemiol. Health 4, 29. doi:10.1186/1745-0179-4-29.

Bota, R.G., Munro, J.S., Sagduyu, K., 2005. Identification of the schizophrenia prodrome in a hospital-based patient population. Mo. Med. 102, 142-146.

Brunet, K., Birchwood, M., Lester, H., Thornhill, K., 2007. Delays in mental health services and duration of untreated psychosis. Psychiatr. Bull. 31, 408-410.

DeLisi, L.E., 1992. The significance of age of onset for schizophrenia. Schizophr. Bull. 18 209-215.

Eaton, W.W., Hall, A.L.F., MacDonald, R., McKibben, J., 2007. Case identification in psychiatric epidemiology: a review. Int. Rev. Psychiatry 19, 497-507.

French, P., Morrison, A.P., 2004. Early Detection and Cognitive Therapy for People at High Risk of Developing Psychosis: A Treatment Approach. John Wiley \& Sons, London.

French, P., Morrison, A.P., Walford, L., et al., 2003. Cognitive therapy for preventing transition to psychosis in high risk individuals: a case series. Behav. Cogn. Psychother. 31, 53-67.

Häfner, H., 2000. Onset and early course as determinants of the further course of schizophrenia. Acta Psychiatr. Scand. 102, 44-48.

Häfner, H., Maurer, K., Löffler, W., Riecher-Rossler, A., 1993. The influence of sex and age on the onset and early course of psychosis. Br. J. Psychiatry 162, 86.

Häfner, H., Maurer, K., Trendler, G., An der Heiden, W., Schmidt, M.H., Könnecke, R. 2005a. Schizophrenia and depression: challenging the paradigm of two separate diseases-a controlled study of schizophrenia, depression and healthy controls. Schizophr. Res. 77, 11-24.

Häfner, H., Maurer, K., Trendler, K., An der Heiden, W., Schmidt, M.H., 2005b. The early course of schizophrenia and depression. Eur. Arch. Psychiatry Clin. Neurosci. 255, 167-173.

Hanssen, M., Bak, M., Bijl, R.V., Vollenberg, W., Van Os, J., 2005. The incidence and outcome of subclinical psychotic experiences in the general population. Br. J. Clin. Psychol. 44, 181-191.

Harrison, P.J., Weinberger, R., 2005. Schizophrenia genes, gene expression, and neuropathology: on the matter of their convergence. Mol. Psychiatry 10, 40-68.

Keshavan, M.S., Diwadar, V.A., Montrose, D.M., Rajarethinam, R., Sweeney, J.A., 2005. Premorbid indicators and risk for schizophrenia: a selective review and update. Schizophr. Res. 79, 45-57.

Klosterkötter, J., Hellmich, M., Steinmeyer, E.M., Schultze-Lutter, F., 2001. Diagnosing schizophrenia in the initial prodromal phase. Arch. Gen. Psychiatry 58, 158-164.

Krabbendam, L., Van Os, J., 2005. Affective processes in the onset and persistence of psychosis. Eur. Arch. Psychiatry Clin. Neurosci. 255, 185-188. 
Lane, J.M., Addis, M.E., 2005. Male gender role conflict and patterns of help seeking in Costa Rica and the United States. Psychol. Men Masc. 6, 155-168.

McGorry, P.D., Yung, A.R., Phillips, L.J., 2003. The 'close-in' or ultra high-risk model: a safe and effective strategy for research and clinical intervention in prepsychotic mental disorders. Schizophr. Bull. 29, 771-790.

McGorry, P.D., Killackey, E.J., Yung, A.R., 2008. Early intervention in psychosis: concepts, evidence and future directions. World Psychiatr. 7, 148-156.

Moore, T.H.M., Zammit, S., Lingford-Hughes, A., Barnes, T.R., Jones, P., Burke, M., Lewis, G., 2007. Cannabis use and risk of psychotic or affective mental health outcomes: review. Lancet 370, 319-328.

Morrison, A.P., Steward, S.L.K., French, P., Bentall, R.P., Birchwood, M., Byrne, R. Davies, L.M., Fowler, D., Gumley, A., Jones, P.B., Murray, G.K., Patterson, P., Dunn, G., 2011. Early detection and intervention evaluation for people at high risk of psychosis-2 (EDIE-2): trial rationale, design and baseline characteristics. Early Interv. Psychiatry 5, 24-32.

Murphy, J., Shevlin, M., Houston, J., Adamson, G., 2010. A population based analysis of subclinical psychosis and help-seeking behavior. Schizophr. Bull. doi:10.1093/ schbul/sbq092.

Murray, R.M., Morrison, P.D., Henquet, C., Di Forti, M., 2010. Cannabis, the mind and society: the hash realities. Nat. Rev. Neurosci. 8, 885-895.

Nieman, D.H., Rieke, W.H., Becker, H.E., Dingemans, P.M., Van Amelsvoort, T.A., De Haan, L, Van der Gaag, M., Denys, D.A.J.P., Linszen, D.H., 2009. Prescription of antipsychotic medication to patients at ultra high risk of developing psychosis. Int. Clin. Psychopharmacol. 24, 223-228.

Norman, R.M.G., Malla, A.K., Verdi, M.B., Hassall, L.D., Fazekas, C., 2004. Understanding delay in treatment for first episode psychosis. Psychol. Med. 34, 255-266.

Platz, C., Umbricht, D.S., Cattapan-Ludewig, K., Dvorsky, D., Archbach, D., Brenner, H.-D. Simon, A.E., 2006. Help-seeking pathways in early psychosis. Soc. Psychiatry Psychiatr. Epidemiol. 41, 974.
Preda, A., Miller, T.J., Rosen, J.L., Somjee, L., McGlashan, T.H., Woods, S.W., 2002. Treatment histories of patients with a syndrome putatively prodromal for schizophrenia. Psychiatr. Serv. 53, 342-344.

Stip, E., Letourneau, G., 2009. Psychotic symptoms as a continuum between normality and pathology. Can. J. Psychol. 54, 140-151.

Van Os, J., Delespaul, P., 2005. Toward a world consensus on prevention of schizophrenia. Dialogues Clin. Neurosci. 7, 53-67.

Van Os, J., Hanssen, M., Bijl, R.V., Ravelli, A., 2000. Strauss (1969) revisited: a psychosis continuum in the general population? Schizophr. Res. 45, 11-20.

Van Os, J., Kenis, G., Rutten, B.P., 2010. The environment and schizophrenia. Nature 468, 203-212.

Velthorst, E., Nieman, D.H., Linszen, D.H., Becker, H.E., De Haan, L., 2010. Disability in people clinically at high risk of psychosis. Br. J. Psychiatry 197, 278-284.

Volleberg, W.A.M., de Graaf, R., Ten Have, M., Schoenmaker, C.G., van Dorsselear, S., Spijker, J., Beekman, A.T.F., 2010. [in Dutch] Psychische stoornissen in Nederland. Trimbos Institute, Utrecht.

Yung, A.R., Yuen, H.P., McGorry, P.D., Phillips, L.J., Kelly, D., Dell'Olio, M., Francey, S.M., Cosgrave, E.M., Killackey, E.J., Stanford, C., Godfrey, K., Buckby, J.A., 2005. Mapping the onset of psychosis-the Comprehensive Assessment of at Risk Mental States (CAARMS). Aust. N. Z. J. Psychiatry 39, 964-971.

Yung, A.R., Buckby, J.A., Cotton, S.M., Cosgrave, E.M., Killackey, E.J., Stanford, C., Godfrey, K., McGorry, P.D., 2006. Psychotic-like experiences in non-psychotic help-seekers: associations with distress, depression, and disability. Schizophr. Bull. 32, 352-359.

Yung, A.R., Phillips, L.J., Nelson, B., Francey, S.M., Yuen, H.P., Simmons, M.B., Ross, M.L., Kelly, D., Dip, G., Baker, K., Amminger, P., Berger, G., Thompson, A.D., Thampi, A., McGorry, P.D., 2011. Randomized controlled trial of interventions for young people at ultra high risk for psychosis: 6-months analysis. J. Clin. Psychiatry 72, 430-440. 